\title{
Risk Assessment of Heavy Metal in the Surface Sediment at the Drinking Water Source of the Xiangjiang River in South China
}

\section{CURRENT STATUS: ACCEPTED}

Environmental Sciences Europe Springer

\section{Zhifeng Huang}

Tongji University College of Environmental Science and Engineering

Chengyou Liu

Chinese Research Academy of Environmental Sciences

Xingru Zhao

Chinese Research Academy of Envieronmental Science

zhaoxr@craes.org.cnCorresponding Author

ORCiD: https://orcid.org/0000-0002-5577-4965

Jing Dong

Chinese Research Academy of Environmental Sciences

Binghui Zheng

Chinese Research Academy of Environmental Sciences

DOI:

10.21203/rs.2.19404/v2

SUBJECT AREAS

Environmental Policy

KEYWORDS

Heavy metal, Risk assessment, Sediment, Distribution, The Xiangjiang River 
Abstract

Background: The Xiangjiang River is an important drinking water resource for the Hunan province of China. It is crucial to ascertain the pollution status, influencing factors, ecological risks, and possible sources of heavy metals in the sediments of the Xiangjiang River. Sediment is both a source and a sink of heavy metals in aquatic ecosystems. In this study, surface sediment was collected from the Zhuzhou Reach of the Xiangjiang River and eight heavy metals were investigated.

Results: In all sediment samples, all eight heavy metals were detected and their average concentration fell in the order of $\mathrm{Zn}>\mathrm{Pb}>\mathrm{As}>\mathrm{Cu}>\mathrm{Cr}>\mathrm{Ni}>\mathrm{Cd}>\mathrm{Co}$. Assessment shows extremely serious $\mathrm{Cd}$ pollution and a very high potential ecological risk from Cd. According to correlation analysis and principle component analysis (PCA), $\mathrm{As}, \mathrm{Cu}, \mathrm{Ni}, \mathrm{Pb}$, and $\mathrm{Zn}$ originate from industrial wastewater and mineral smelting activities, whereas $\mathrm{Co}, \mathrm{Cr}$, and $\mathrm{Ni}$ come from natural sources. Redundancy analysis (RDA) reveals that the organic matter content and the particle size of the sediment have some influence on the enrichment of heavy metals.

Conclusion: Among all eight examined heavy metals in the surveyed area, the content of $\mathrm{Zn}, \mathrm{Pb}, \mathrm{and}$ As is the highest, and that of $\mathrm{Cd}$ and $\mathrm{Co}$ is the lowest. Despite a low level of absolute content, the Cd in sediment already renders a high ecological risk and thus calls for urgent attention. Anthropogenic activities are the main source of heavy metals in the sediment. The distribution of heavy metals is also influenced by sediment properties. The results provide guidance for controlling heavy metal pollution and protecting drinking water sources in the Xiangjiang River.

\section{Full-text}

Due to technical limitations, full-text HTML conversion of this manuscript could not be completed. However, the manuscript can be downloaded and accessed as a PDF.

Figures 

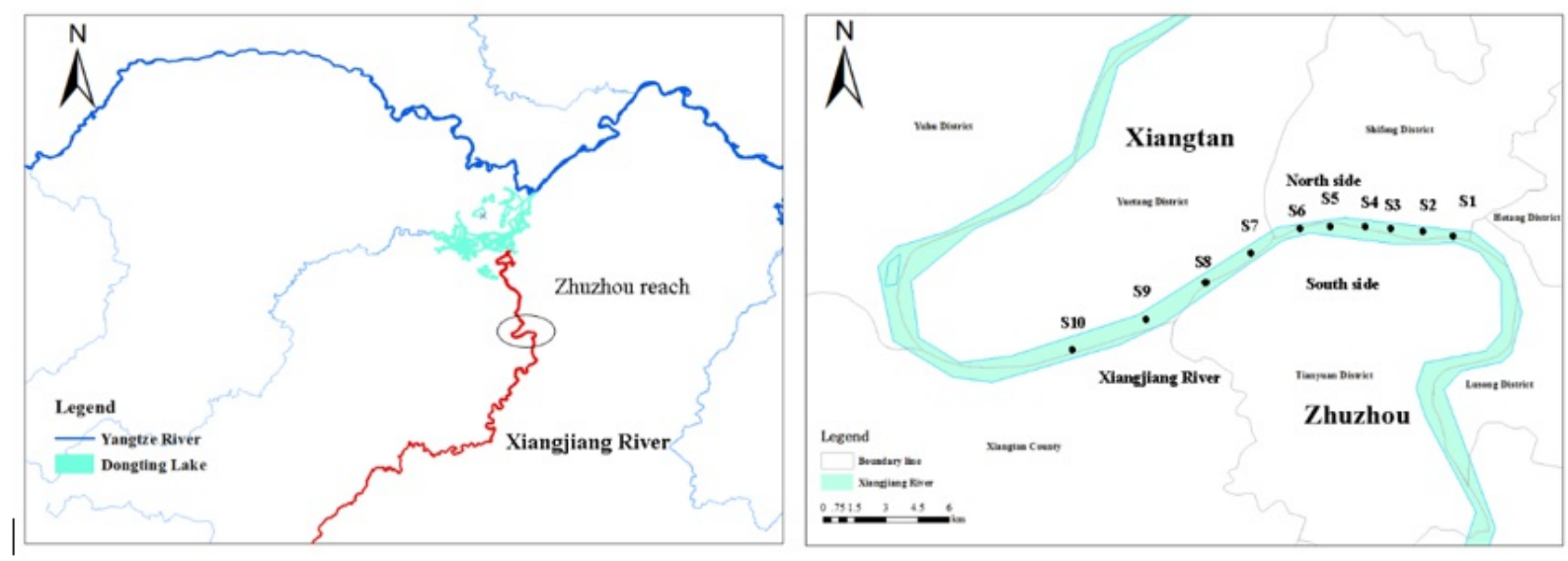

Figure 1

Map of the Xiangjiang River Basin and the sampling sites. Note: The designations employed and the presentation of the material on this map do not imply the expression of any opinion whatsoever on the part of Research Square concerning the legal status of any country, territory, city or area or of its authorities, or concerning the delimitation of its frontiers or boundaries. This map has been provided by the authors. 


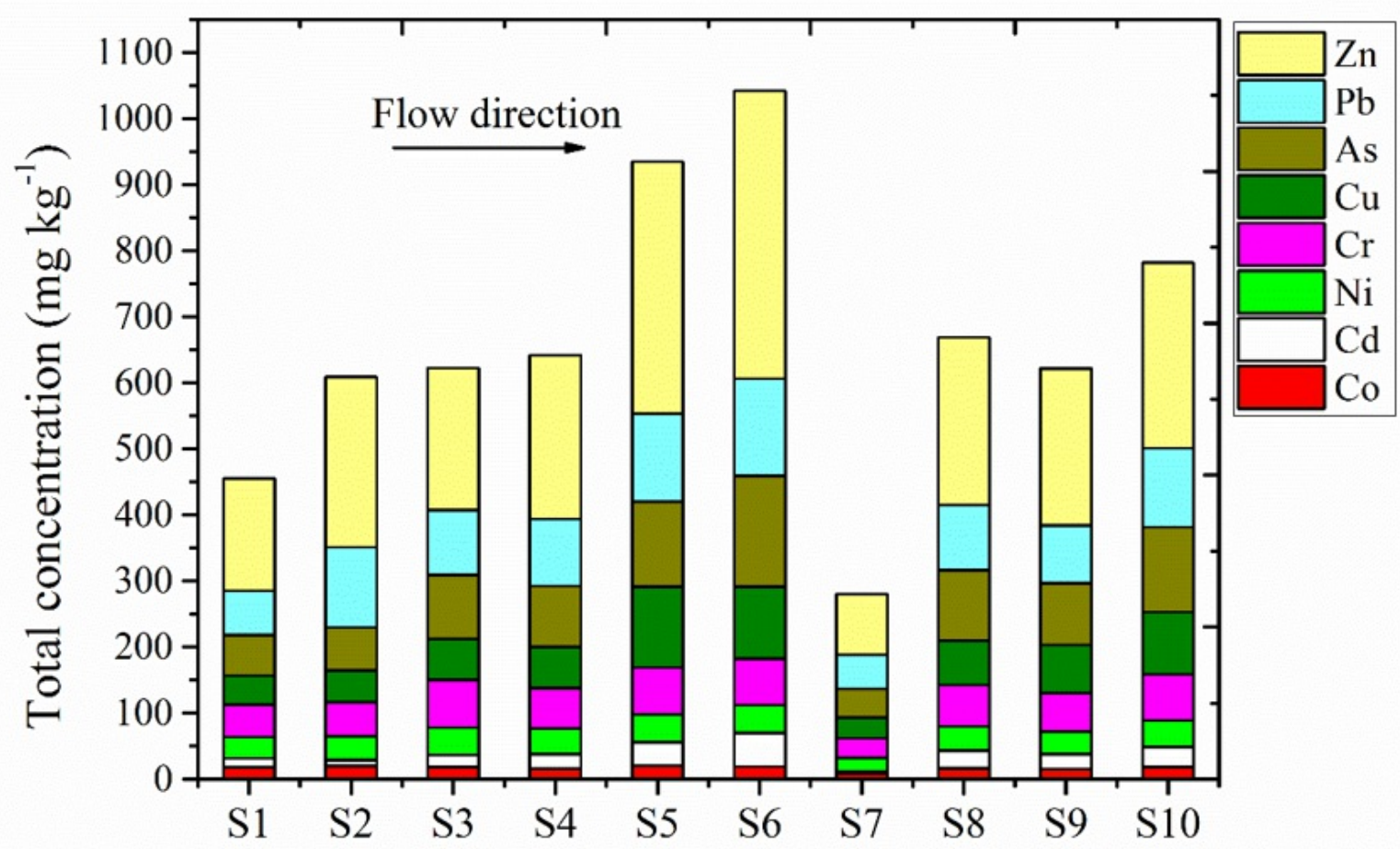

Figure 2

Note: The designations employed and the presentation of the material on this map do not imply the expression of any opinion whatsoever on the part of Research Square concerning the legal status of any country, territory, city or area or of its authorities, or concerning the delimitation of its frontiers or boundaries. This map has been provided by the authors. 


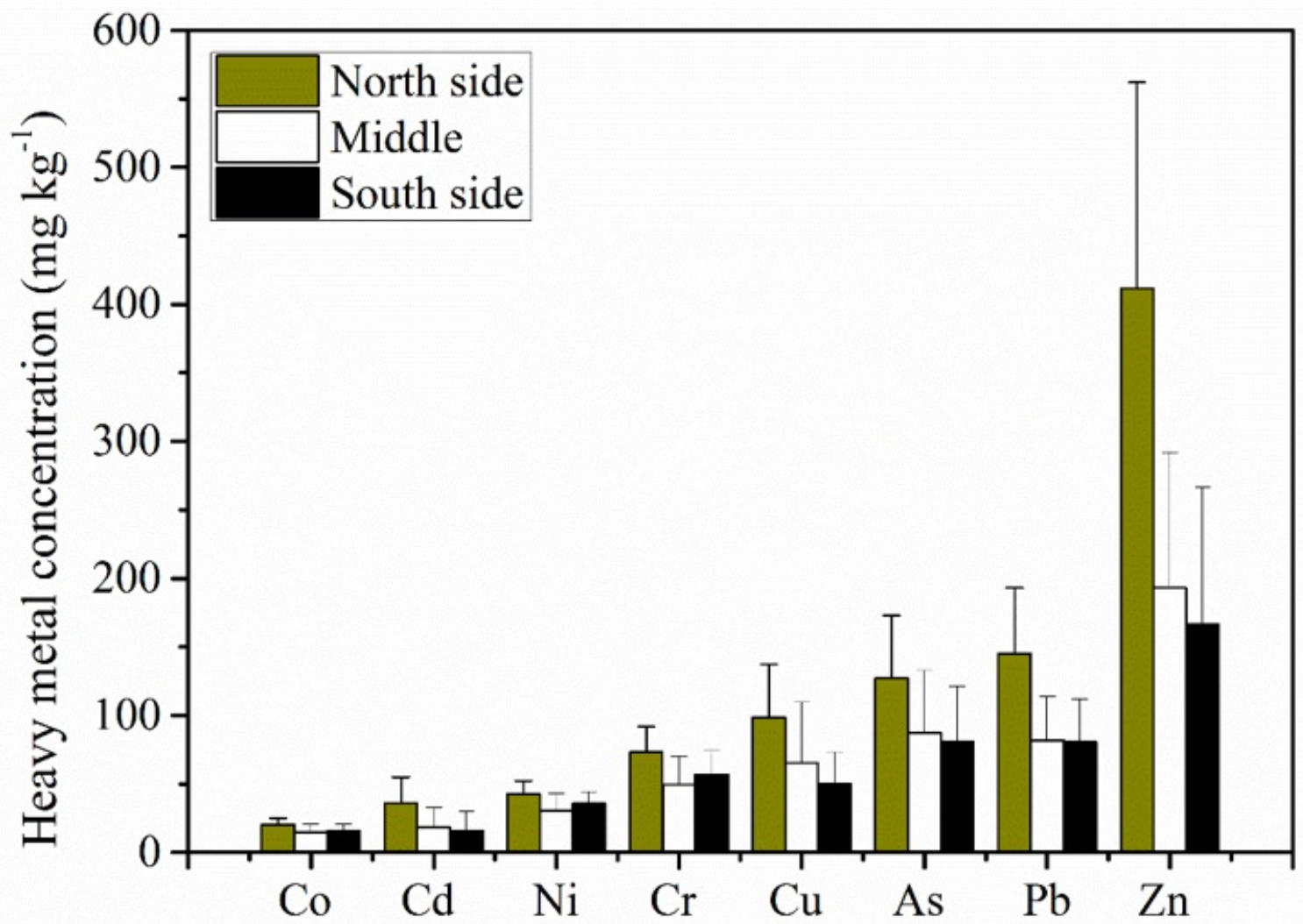

Figure 3

Heavy metal concentration in the sediment collected at the south side, the north side, and in the middle of the river.

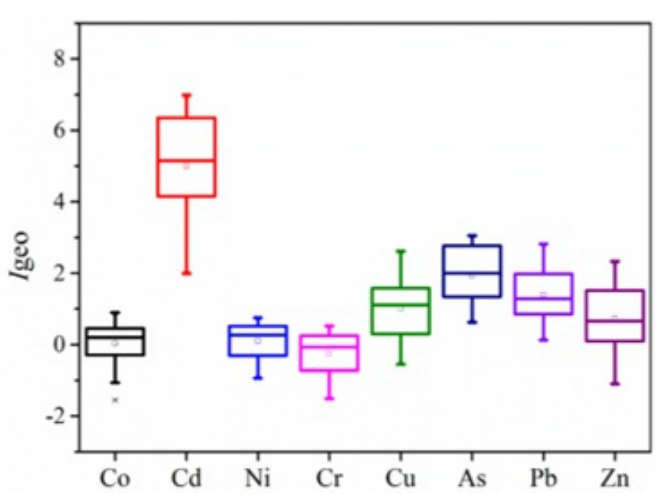

a

\begin{tabular}{|c|c|c|c|c|c|c|c|c|c|}
\hline$I_{g e 0}$ & Co & $\mathrm{Cd}$ & $\mathrm{Ni}$ & $\mathrm{Cr}$ & $\mathrm{Cu}$ & As & $\mathrm{Pb}$ & $\mathrm{Zn}$ & Class \\
\hline S1 & 0.19 & 4.64 & -0.07 & -0.50 & 0.42 & 1.37 & 0.82 & 0.23 & 0 \\
\hline $\mathrm{S} 2$ & 0.27 & 3.82 & 0.09 & -0.47 & 0.42 & 1.46 & 1.44 & 0.54 & 1 \\
\hline S3 & 0.26 & 5.10 & 0.36 & 0.12 & 1.02 & 2.09 & 1.44 & 0.69 & 2 \\
\hline S4 & -0.02 & 5.47 & 0.21 & -0.16 & 1.05 & 2.03 & 1.52 & 0.97 & 3 \\
\hline S5 & 0.29 & 5.66 & 0.32 & 0.02 & 1.56 & 2.29 & 1.82 & 1.30 & 4 \\
\hline S6 & 0.28 & 6.67 & 0.39 & 0.04 & 1.79 & 2.89 & 2.06 & 1.75 & 5 \\
\hline S7 & -0.99 & 2.81 & -0.69 & -1.18 & 0.05 & 0.92 & 0.54 & -0.55 & 6 \\
\hline S8 & 0.05 & 5.20 & 0.16 & -0.15 & 0.96 & 2.11 & 1.40 & 0.73 & \\
\hline S9 & -0.16 & 4.94 & 0.02 & -0.28 & 1.23 & 1.81 & 1.19 & 0.70 & \\
\hline $\mathrm{S} 10$ & 0.21 & 5.76 & 0.30 & 0.04 & 1.61 & 2.43 & 1.72 & 1.06 & \\
\hline
\end{tabular}

b

Figure 4

Box diagram of Igeo values of heavy metals (a), and pollution classies in different sites (b) in the sediment of the Zhuzhou Reach. 


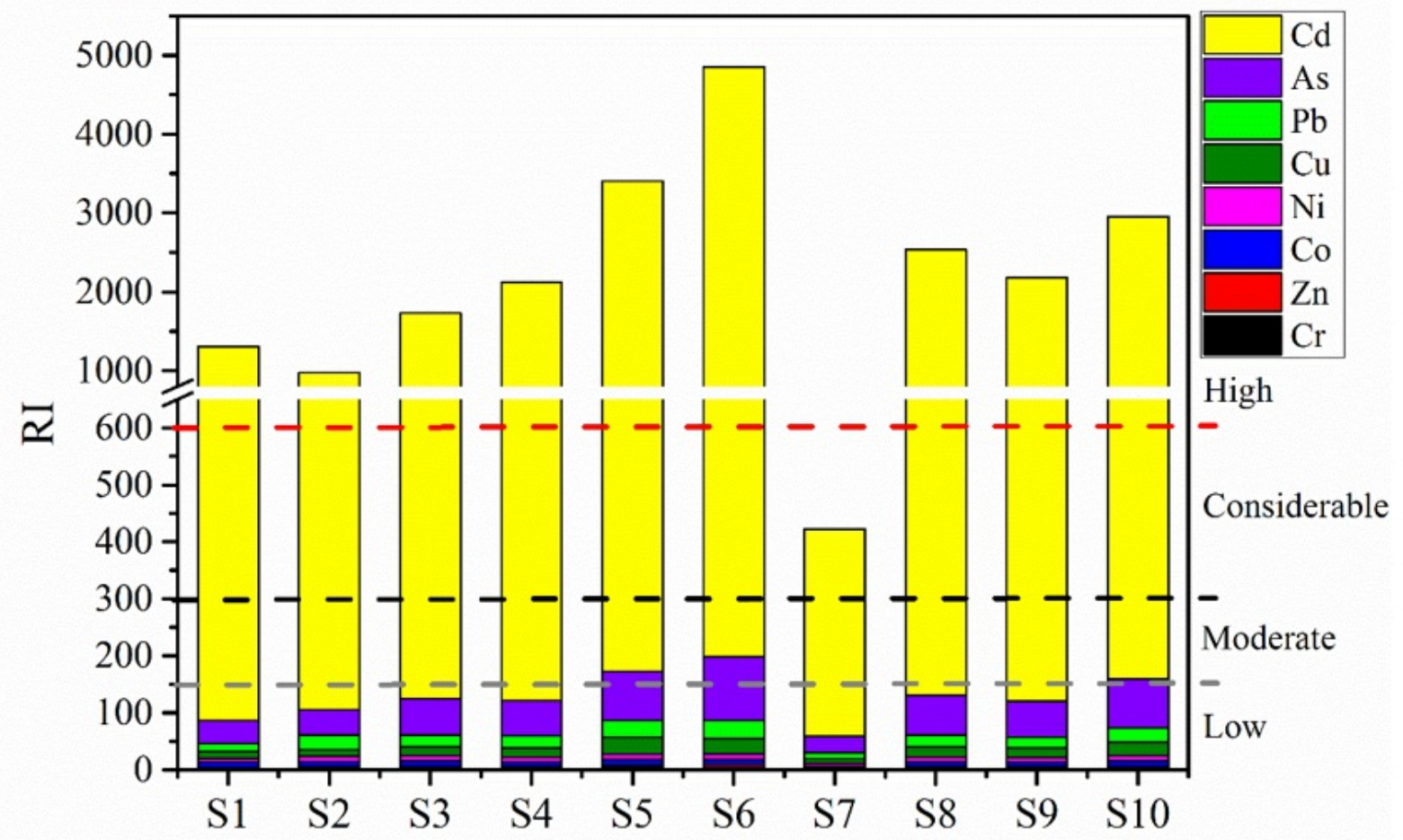

Figure 5

RI values of heavy metals in the sediment (derived from the values) 


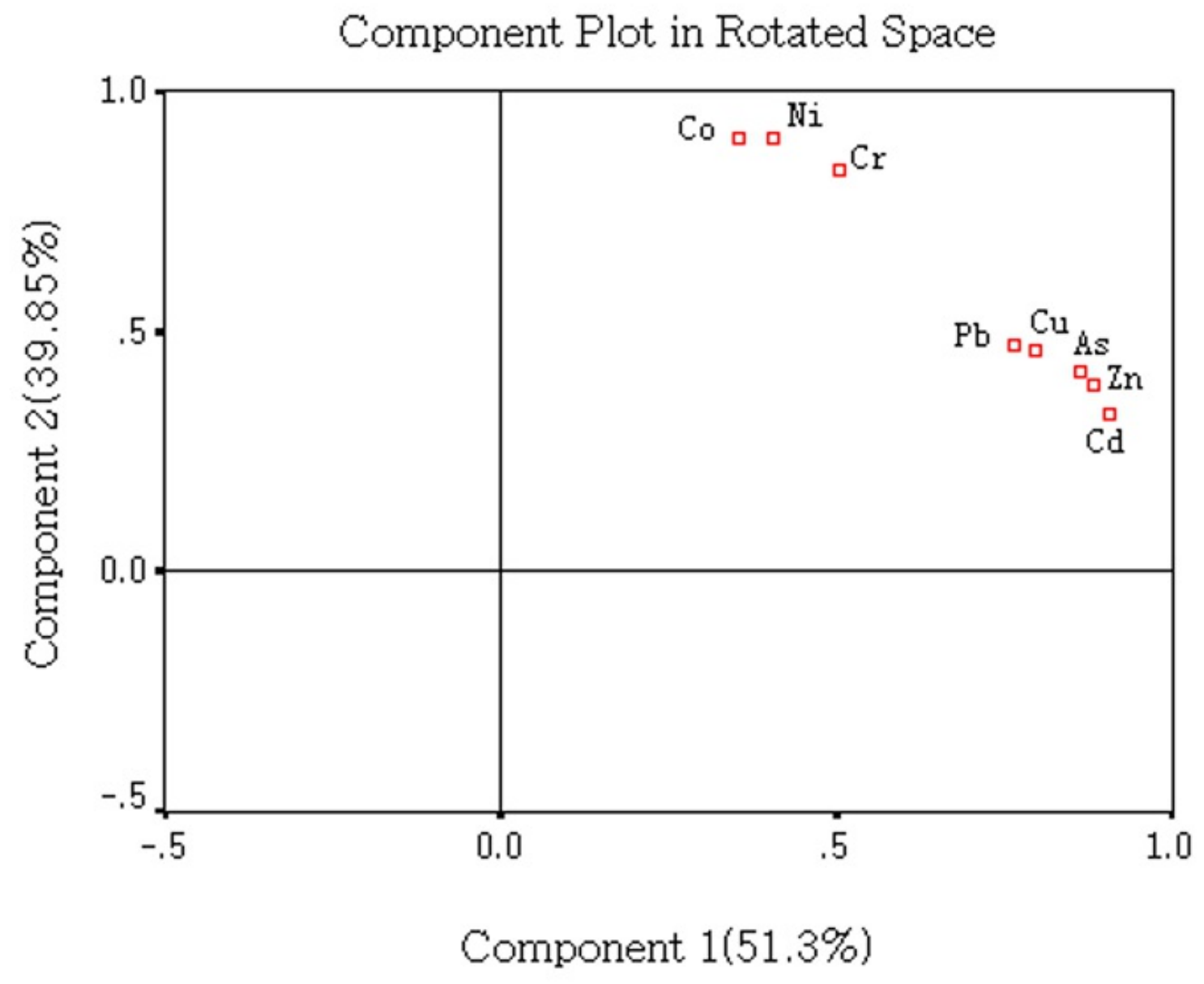

Figure 6

Principal component profile of heavy metals in the sediment of different sampling sites.. 


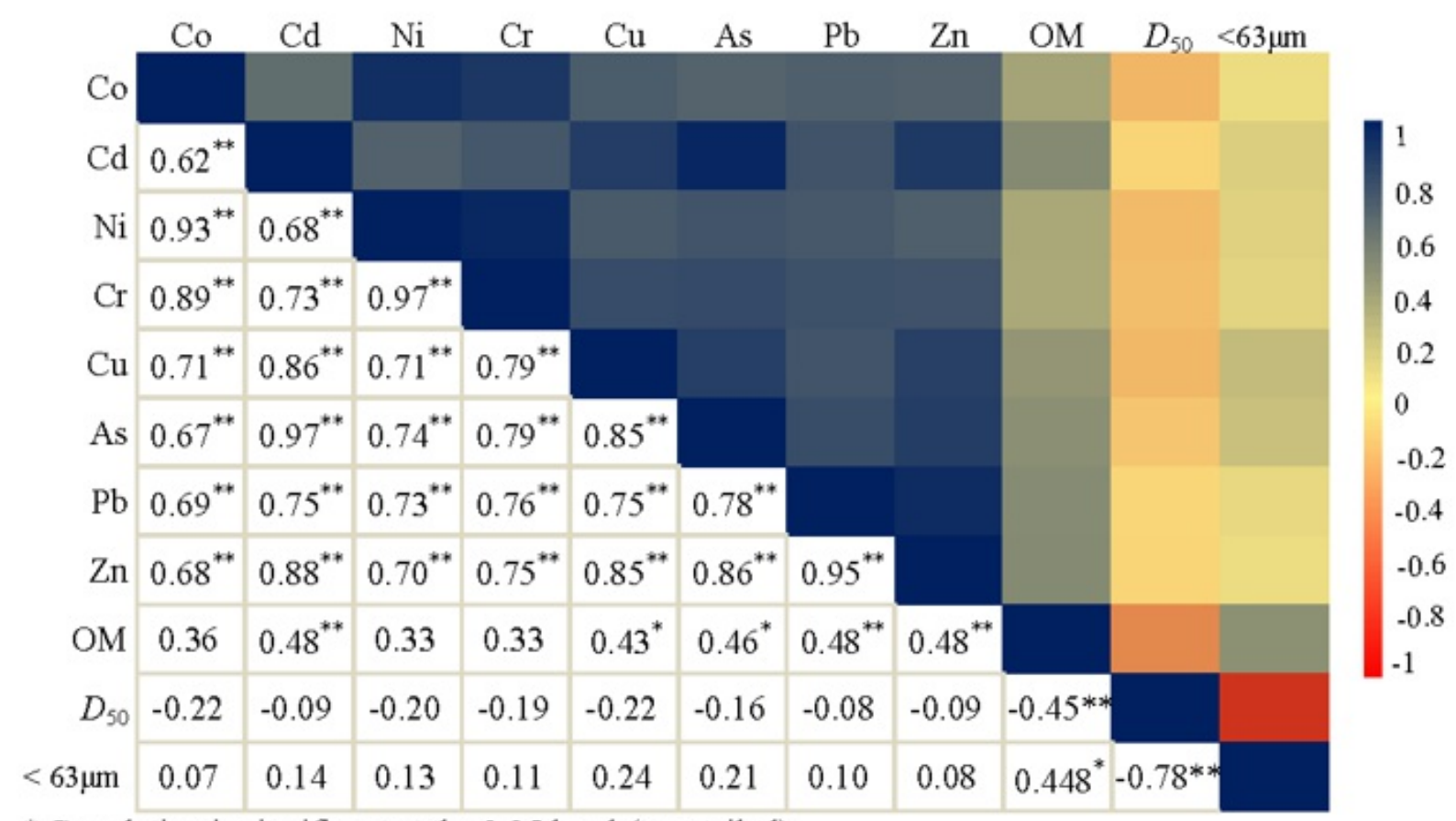

* Correlation is significant at the 0.05 level (two-tailed),

** Correlation is significant at the 0.01 level (two-tailed).

Figure 7

Pearson's correlation coefficients $(r)$ of heavy metals and environmental factors in the sediment of the Zhuzhou Reach. 


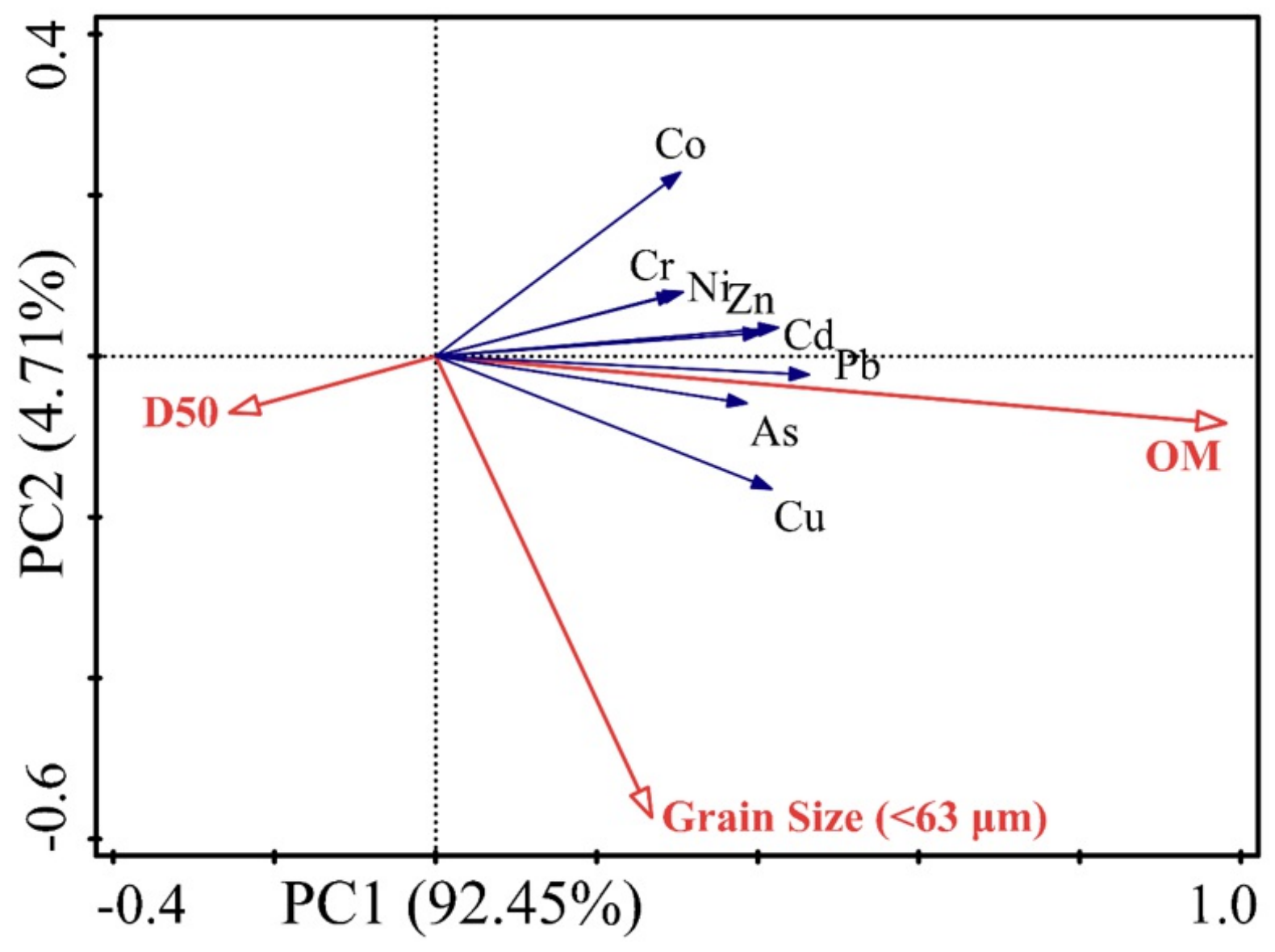

Figure 8

Redundancy analysis diagram between heavy metals and sediment variables.

\section{Supplementary Files}

This is a list of supplementary files associated with this preprint. Click to download.

supplementary material ESEU-D-19-00189(2).docx 